\title{
New Bisbenzylisoquinolines, Fatty Acid Amidic Aporphines, and a Protoberberine from Formosan Cocculus orbiculatus
}

Fang-Rong Chang* and Yang-Chang Wu

Graduate Institute of Natural Products, Kaohsiung Medical University, Kaohsiung

807, Taiwan

Supporting Information.

Figure S1. CD Spectra of Bisbenzylisoquinolines 1-5.

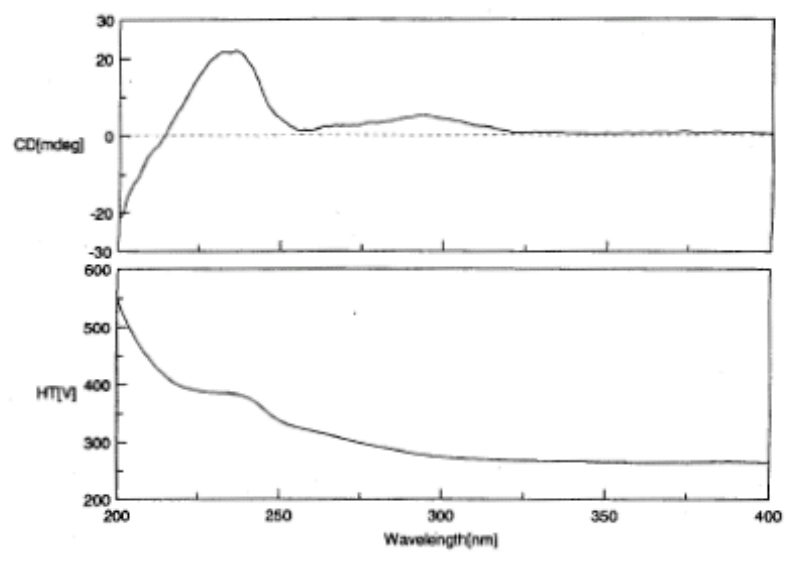

The CD spectrum of (+)-isotrilobine (1)

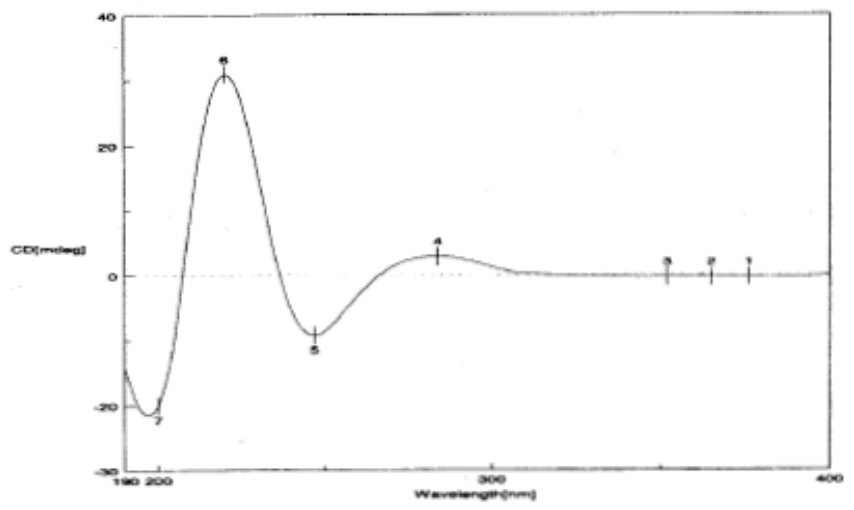

The CD spectrum of (+)-coccuorbiculatine A (2) 


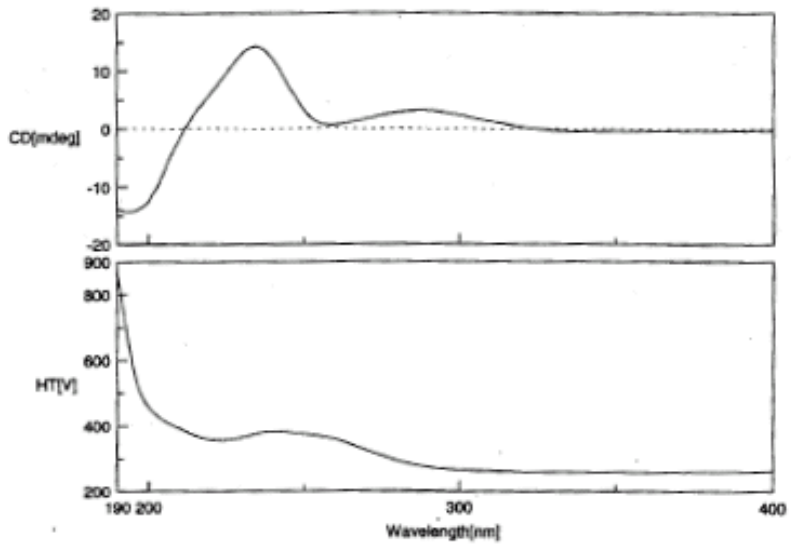

The CD spectrum of (+)-10-hydroxyisotrilobine (3)

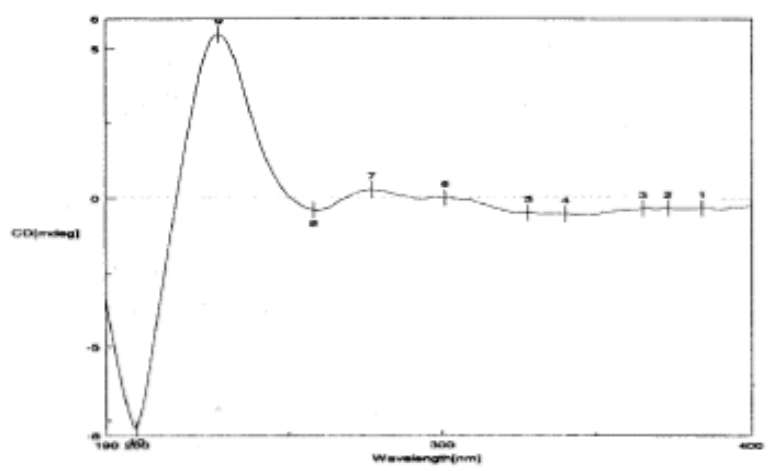

The CD spectrum of (+)-1,2-dehydroapateline (4)

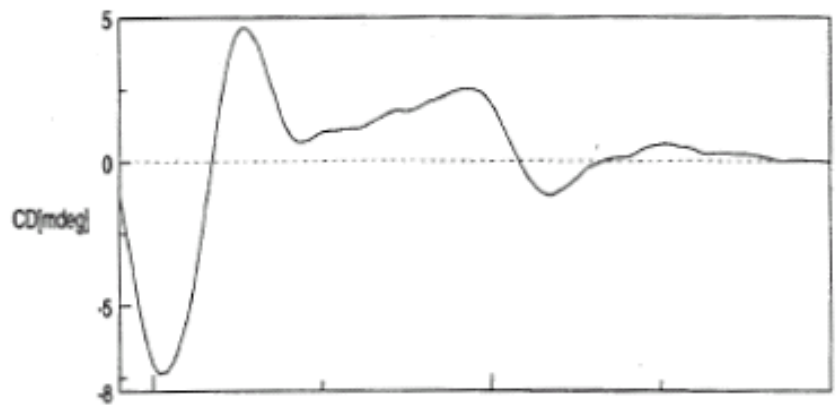

The CD spectrum of (+)-O-methylcocsoline (5) 
Figure S2. The NMR evidence for the rotational isomers of the mixture of $(+)$ laurelliptinhexadecan-1-one (6) and (+)-laurelliptinoctadecan-1-one (7) were carried out. The first figure (original, $600 \mathrm{MHz}$, room temp. in $\mathrm{CDCl}_{3}$ ) indicated that most of signals were separated into two groups (ca. 6:4, two stable conformations). Because the relationship between these isomers and temperature should be clarified, pyridine- $\mathrm{D}_{5}$ was taken as NMR solvent for the thermo-changed measurement. On the second figure $(400 \mathrm{MHz}$, room temp. in pyridine- $\left.\mathrm{D}_{5}\right)$, the splitting still exist in some of signals. However, in the third figure $\left(400 \mathrm{MHz}, 75^{\circ} \mathrm{C}\right.$ in pyridine- $\left.\mathrm{D}_{5}\right)$, three aromatic signals (the middle one was interrupted by one of the pyridine signals) show no splitting. At this situation, the aliphatic signals near amidic function become broad. It was probably caused by the rapid rotation or existing conformations.

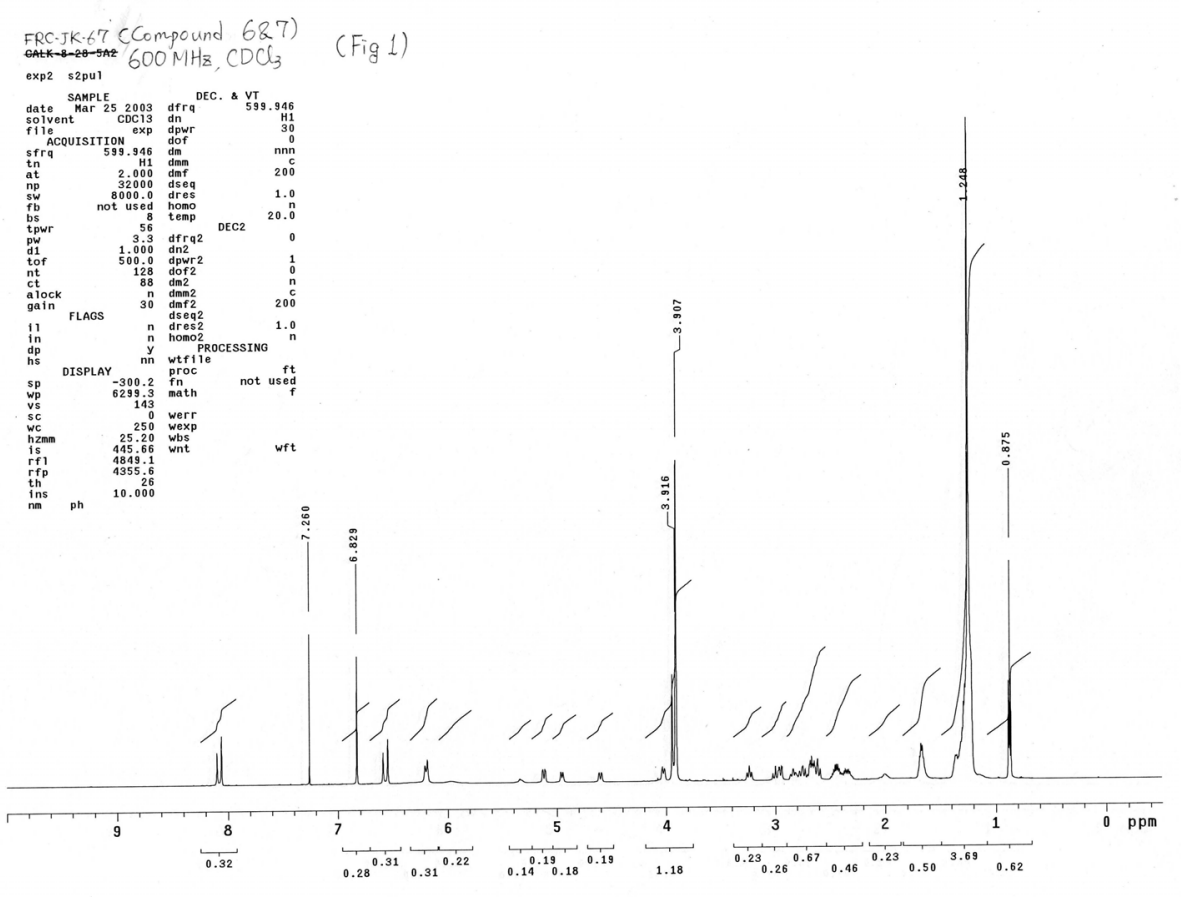



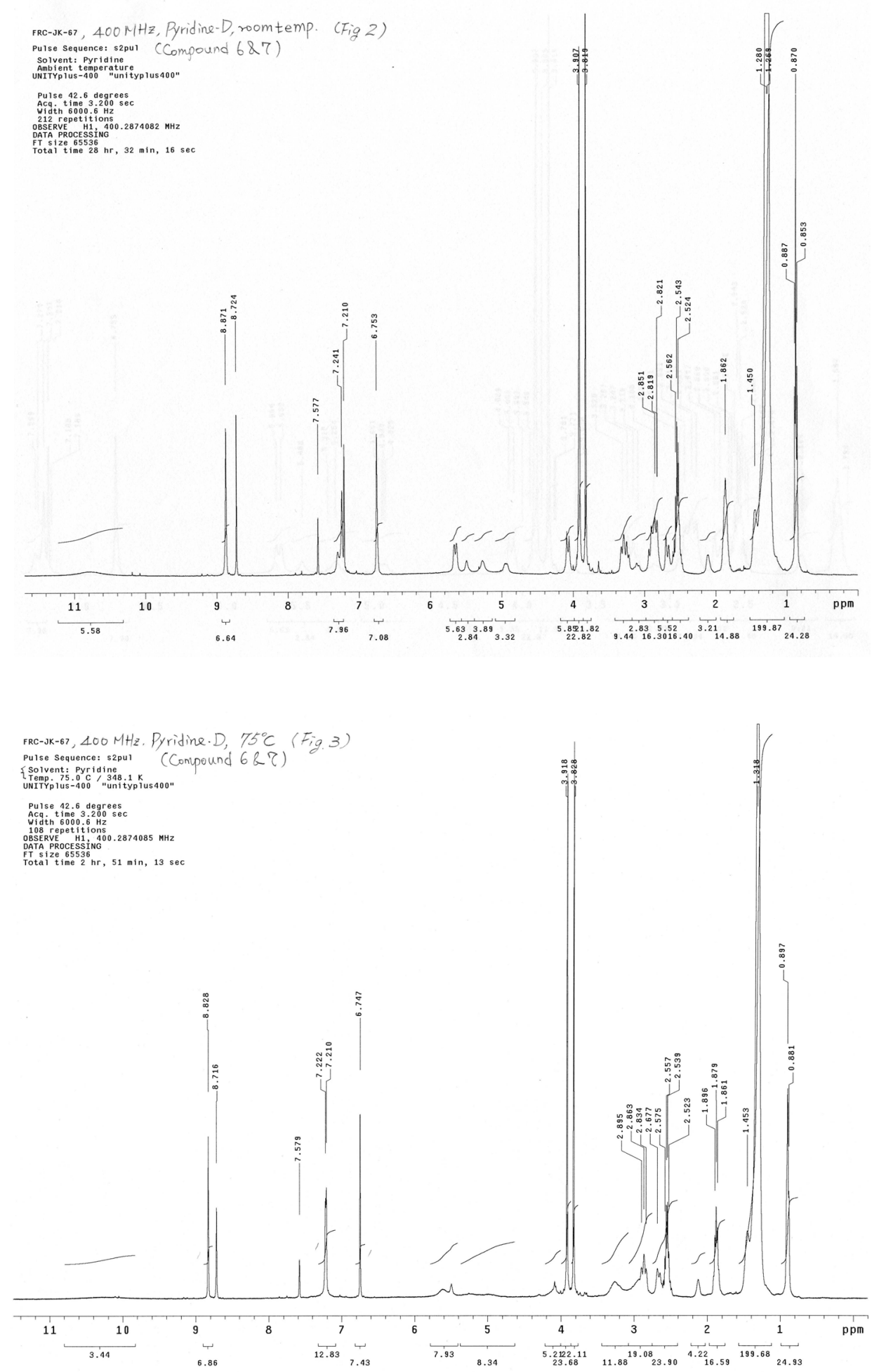
In addition, other nine compounds, (+)-coclaurine (6 mg, $n$-hexane- $\mathrm{CHCl}_{3} 1: 5, \mathrm{R}_{f}$ 0.48), ${ }^{\mathrm{s} 1} \quad N$-trans-feruloyltyramine $\left(23 \mathrm{mg}, \mathrm{CHCl}_{3}-\mathrm{MeOH} \quad 20: 1, \mathrm{R}_{f} \quad 0.4\right),{ }^{\mathrm{s} 2} \quad(-)$ syringaresinol $(15 \mathrm{mg}),{ }^{\mathrm{s} 3}(+)$-dia-syringaresinol $(11.0 \mathrm{mg}),{ }^{\mathrm{s} 3}(+)$-epi-syringaresinol $(15 \mathrm{mg}),{ }^{\mathrm{s} 3} 4$-allyl-2,6-dimethoxy-phenol (7 mg, $n$-hexane-CHCl $\left.1: 1, \mathrm{R}_{f} 0.5\right){ }^{\mathrm{s} 4} 3,4,5$ trimethoxy-benzoic acid (16 $\mathrm{mg}, n$-hexane- $\left.\mathrm{CHCl}_{3} 2: 1, \mathrm{R}_{f} 0.56\right),{ }^{\mathrm{s} 5}$ phytosterols (13 mg, $n$-hexane- $\mathrm{CHCl}_{3} 1: 3, \mathrm{R}_{f} 0.45$ ), ${ }^{\mathrm{s} 5}$ and $\beta$-sitosteryl- $\beta$-D-glucoside (40 mg, $\mathrm{CHCl}_{3}$ $\mathrm{MeOH} 6: 1, \mathrm{R}_{f}$ 0.40), ${ }^{\mathrm{s} 5}$ were also isolated from this plant. The structures of these known compounds were determined by their spectroscopic data.

References

(s1) Wu, Y. C.; Chang, F. R.; Chen, K. S.; Ko, F. N.; Teng, C. M. Chin. Pharm. J. (Taipei, Taiwan) 1994, 46, 439-446.

(s2) Chen, C. Y.; Chang, F. R.; Wu, Y. C. J. Chin. Chem. Soc. (Taipei, Taiwan) 1997, $44,313-319$.

(s3) Chang, F. R.; Chao, Y. C.; Teng, C. M.; Wu, Y. C. J. Nat. Prod. 1998, 61, 863866.

(s4) Jing, X.; Gu, W.; Ren, X.; Bie, P.; Pan, X. J. Chin. Chem. Soc. (Taipei, Taiwan) 2001, 48, 59-63.

(s5) Chang, Y. C.; Chang, F. R.; Wu, Y. C. J. Chin. Chem. Soc. (Taipei, Taiwan) 2000, 47, 373-380. 